\title{
Measurement and control of tennis training load: a case study
}

\author{
Cyril Genevois ${ }^{a}$, Isabelle Rogowski, ${ }^{\text {a }}$ \& Tom Le Solliec \\ ${ }^{\text {a }}$ Claude Bernard University Lyon 1, Lyon, France.
}

\section{ABSTRACT}

The objective of this study was to quantify the training load involved in tennis training using relatively simple tools to provide practical information to coaches on the calculation and optimization of the training load, paying particular attention to the session-RPE method, the calculation of the monotony index and the acute to chronic workload ratio calculation. This article presents a case study of a 16-year-old player combining his education with his training in a tennis academy as well as with competition. The daily and weekly training load as well as the other indicators were calculated over 31 weeks and then explained, interpreted and discussed in this article.

\author{
Key words: RPE, training load, \\ monitoring, monotony, ACWR. \\ Received: 26 November 2019 \\ Accepted: 10 January 2020 \\ Corresponding author: Cyril \\ Genevois, 6 Grande rue de \\ Saint Clair, Caluire-et-Cuire, \\ Lyon, France 69300. Email: \\ cyril.genevois@aol.fr
}

\section{INTRODUCTION}

The appropriate application of the training load $(T L)$ is one of the fundamental factors in inducing beneficial physiological adaptations and improved performance. Insufficient loads do not bring about physiological adaptations, and excessive loads lead to harmful adaptations, such as a state of non-functional fatigue and/or a state of overtraining.

Considering the wide variety of exercises used both in technical-tactical training and in the physical conditioning of the tennis player, the measurement of TL is a challenge. The session-RPE (Rating of Perceived Exertion) method proposed by Foster et al. (2001), which is based on the post-session perception of the session's intensity and its duration, makes it possible to quantify the TL of different types of training by expressing it in arbitrary units (AU). It has been validated in several sports with men and women of different age categories and with various levels of expertise (Haddad et al, 2017), and in tennis with Elite players (Gomes et al, 2015). From a practical point of view, 30 minutes after the session, the player answers the question: "How did you feel the session on a scale of 1 to 10 ?" - the scale proposed by Borg et al. (1982). The TL of the session is then calculated as the product of the duration of the session (expressed in minutes) and the RPE. As a result, the higher the result obtained in the RPE, the higher the perceived TL.
Training load control is important from one session to the next but also from week to week and month to month to find a balance between fatigue and recovery. Since tennis injuries are mainly over-stress injuries, the goal is to find a threshold that allows both the optimization the player's training capacity while protecting him or her from the risk of injury. The Monotony Index provides an overview of the variability in training throughout the week. It is calculated by dividing the average daily $T L$ for the week by its standard deviation. A weak index with large variations from one day to the next is to be sought, and it is advisable not to exceed a value of 2 (Foster, 1998). The acute load / chronic workload ratio (ACWR) is an indicator that compares the training load of the current week (acute) with the average of the previous 4 weeks (chronic). A ratio between 0.8 and 1.3 would be considered a target area in which the TL is high enough to cause beneficial adaptations but not enough to generate harmful adaptations like increasing the risk of injury (Blanch \& Gabett, 2016).

The objective of this study was to quantify the size and the variation of the TL using the RPE session method, the monotony index and the acute load / chronic load ratio over 31 weeks in a 16-year-old high school player. 


\section{METHOD}

The case studied a tennis player training in an academy (16 years old, weighing $51 \mathrm{~kg}$, measuring $168 \mathrm{~cm}$, with 9 years of practice, 10 hours of weekly training and an ITN3 ranking) following a traditional high school schedule (30 hours of lessons including 2 hours of P.E. per week). During the 31 weeks of the study, the player accumulated 78 technicaltactical training sessions, 75 physical training sessions and 50 competitive matches. Physical endurance (30/15 IFT) and strength (Squat and Deadlift) tests were performed in weeks 1,16 and 29 to assess the effectiveness of the training. The EC for each session was calculated by multiplying the RPE score by the duration of the session in minutes. These data were then used to calculate the weekly monotony index and the acute to chronic workload ratio (ACWR).

\section{RESULTS}

Table 1 presents an example of a summary table used to calculate and analyse the training loads per session, daily and weekly.

\begin{tabular}{|c|c|c|c|c|c|}
\hline Day & Session & $\begin{array}{l}\text { Session } \\
\text { RPE }\end{array}$ & $\begin{array}{l}\text { Session } \\
\text { duration }\end{array}$ & $\begin{array}{l}\text { Session } \\
\text { workload }\end{array}$ & $\begin{array}{l}\text { Daily } \\
\text { workload }\end{array}$ \\
\hline \multirow{2}{*}{$\begin{array}{l}\text { Monday } \\
8 / 10\end{array}$} & Tennis & 4 & 90 & 360 & \multirow[t]{2}{*}{720} \\
\hline & Strength & 6 & 60 & 360 & \\
\hline \multirow{2}{*}{$\begin{array}{l}\text { Tuesday } \\
9 / 10 \\
\end{array}$} & Tennis & 3 & 90 & 270 & \multirow[t]{2}{*}{630} \\
\hline & Endurance & 6 & 60 & 360 & \\
\hline $\begin{array}{l}\text { Wednesday } \\
10 / 10\end{array}$ & Rest day & 0 & 0 & 0 & 0 \\
\hline \multirow{2}{*}{$\begin{array}{l}\text { Thursday } \\
11 / 10\end{array}$} & Tennis & 4 & 90 & 360 & \multirow[t]{2}{*}{720} \\
\hline & Endurance & 6 & 60 & 360 & \\
\hline \multirow{2}{*}{$\begin{array}{l}\text { Friday } \\
12 / 10\end{array}$} & Tennis & 2 & 90 & 180 & \multirow[t]{2}{*}{420} \\
\hline & Strength & 4 & 60 & 240 & \\
\hline $\begin{array}{l}\text { Saturday } \\
13 / 10\end{array}$ & Competition & 5 & 90 & 450 & 450 \\
\hline $\begin{array}{l}\text { Sunday } \\
14 / 10\end{array}$ & Rest day & 0 & 0 & 0 & \\
\hline \multicolumn{5}{|c|}{ Weekly workload } & 2940 \\
\hline
\end{tabular}

Table 1: Example of a weekly training workload summary

Figure 1 shows the distribution of weekly training loads as well as the change in the monotony index and the acute to chronic workload ratio (ACWR) throughout the 31 weeks.

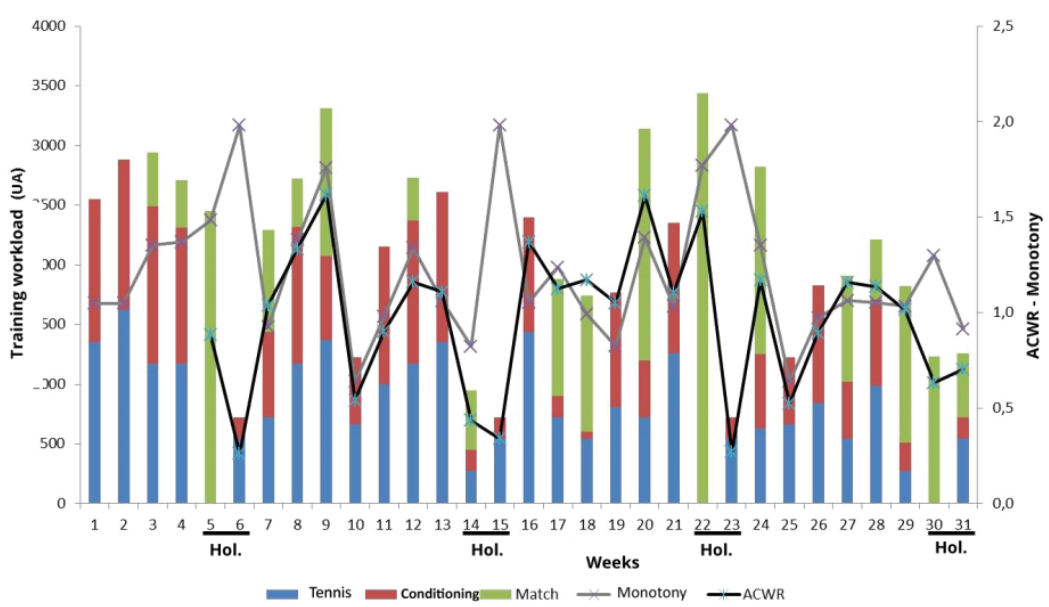

Figure 1: Total weekly workload (bars), monotony index (grey curve) and ACWR ratio (black curve) for 31 weeks. The underlined weeks (VS) are holiday weeks outside the academy.

The average weekly training load during the 31 weeks was $2105 \pm 787$ UA, varying from 720 UA to 3440 UA. The average monotony index was $1.2 \pm 0.4$ (minimum: 0.64; maximum: 1.98). The ACWR ratio was $0.97 \pm 0.39$. Values outside the theoretical target area (0.8-1.3) were observed for 11 weeks out of the 31 studied: three higher values (between 1.49 and 1.63) for weeks 9,20 and 22 and eight lower values (between 0.34 and 0.60) for weeks 6, 10, 14, 15, 23, 25, 30 and 31.

Figure 2 shows the distribution of average RPE values, duration and training load for the different types of session.
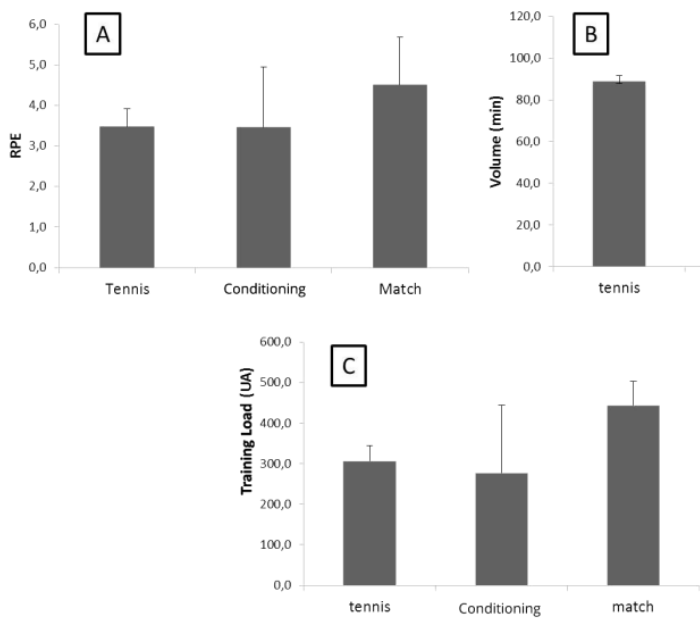

Figure 2: Average values ( \pm standard deviations) in RPE (A), volume (B) and load (C) for technical-tactical sessions, conditioning sessions and competitive matches over the 31 weeks. 
Higher average values of RPE, duration and training load were observed for the matches when compared with technicaltactical sessions and the physical conditioning sessions. A greater average value of session duration was observed for the technical-tactical sessions in comparison with the physical preparation sessions.

Table 2 presents the results of the player's physical tests and highlights an increase in endurance and strength.

\begin{tabular}{|l|l|l|l|}
\hline Tests & Week 1 & Week 16 & Week 29 \\
\hline Squat (\% BW) & 57.7 & 115.4 & 134.6 \\
\hline $\begin{array}{l}\text { Deadlift (\% } \\
\text { BW) }\end{array}$ & 57.7 & 79.6 & 105.8 \\
\hline $\begin{array}{l}30 / 15 \quad \text { ITF } \\
(\mathrm{km} / \mathrm{h})\end{array}$ & 17 & 18.5 & 19 \\
\hline
\end{tabular}

Table 2: Summary table of physical strength as a percentage of bodyweight (BW) and endurance (in $\mathrm{km} / \mathrm{h}$ ) test results at three moments during the season.

\section{DISCUSSION}

The aim of this case study was to quantify the training load with the session-RPE method and analyse its evolution over 31 weeks using the acute to chronic workload ratio in a 16year-old player at high school. The results revealed an average weekly training load of $2105 \mathrm{AU}$, and an average ACWR of 0.97 with $35 \%$ of the total training weeks outside the target zone. They also revealed that the values of RPE and average load of the technical-tactical and physical sessions were significantly lower than those of the matches.

Our results are relatively comparable to those of other studies in tennis (Gomes et al, 2015; Murphy et al, 2016; Coutts et al, 2010; Gomes et al, 2011) or on physical preparation (Lockie et al, 2012; Kilpatrick et al, 2015; Singh et al, 2007). They can therefore be used as a reference for planning training loads. On the other hand, it is important to understand that the weekly TLs depend on the number of hours of training and that they can therefore vary greatly depending on the level of involvement of players in practice (Fett et al, 2017). However, the average values of RPE and training loads for technicaltactical sessions and matches are lower than those observed for a very similar average duration for players of the same age at national level (Perri et al, 2018; Murphy et al, 2015). In addition, as previously presented, the RPE and average load values of the technical-tactical sessions were significantly lower than those of the matches, suggesting a lack of adaptation of the training to the levels of competition. However, the value of the post-session RPE can be impacted by physical exercises in technical-tactical sessions (Murphy et al, 2014). It would therefore be interesting to consider the relative RPE and the duration of the exercises in order to prescribe situations which allow approximation of training to the levels of competition.

The weekly monotony index reflects the daily change in TL. The highest values were obtained during holiday weeks when training was significantly reduced and therefore posed no significant risk. It is interesting to note that the RPE values of the physical preparation sessions are more dispersed than those of the technical-technical sessions and could therefore be the main factor of variability. In view of these results, coaches could be advised to bring more variety in the intensity of the technical-tactical sessions.

The acute to chronic workload ratio (AWCR) remains mainly in the targeted area (0.8-1.3). The values below this threshold correspond to weeks of school holidays (weeks 6, 15 and 23) where the player was not present at the academy and had to perform sessions independently. The values above the threshold correspond to weeks with several competitive matches. As the variability in the duration and intensity of competitive matches is difficult to predict, an analysis a posteriori should allow coaches to adapt training sessions for the following week to stay within optimal ratio values.

During the 31 weeks, the player was never absent (no injuries), progressed on physical tests, and had a win / loss ratio of 1.9 including 13 wins against players ranked higher than him. We can therefore conclude that, in addition to the player's development being linked to his growth, the organisation of its training load has enabled him to adapt effectively by improving his performance and avoiding injury.

\section{CONCLUSION}

The purpose of this case study was to introduce coaches to a simple method of quantifying tennis training load and its indicators in order to analyse variations over time. More research involving different levels of play and age categories is needed to establish benchmarks and to improve and develop workload planning methods in our sport.

\section{REFERENCES}

Blanch, P. \& Gabbett, T.J. (2016). Has the athlete trained enough to return to play safely? The acute: chronic workload ratio permits clinicians to quantify a player's risk of subsequent injury. British Journal of Sports Medicine, 50, 471-475, https://doi.org/10.1136/bjsports2015-095445

Borg, G. (1982). Psychophysical bases of perceived exertion. Medicine and science in sports and exercise, 14(5), 377381, https://doi.org/10.1249/00005768-19820500000012

Coutts, A.J., Gomes, R.V., Viveiros, L. \& Aoki, M.S. (2010). 
Monitoring Training Loads in Elite Tennis. Revista Brasileira de Cineantropometria e Desempenho Humano, 12(3), 217-220.

Fett, J., Ulbricht, A., Wiewelhove, T. \& Ferrauti, A. (2017). Athletic performance, training characteristics, and orthopaedic indications in junior tennis Davis Cup players. International Journal of Sports Science \& Coaching, 12(1), 119-129, https://doi.org/10.1177/1747954116684393

Foster, C. (1998). Monitoring training in athletes with reference to overtraining syndrome. Medicine \& Science in Sports \& Exercise, 30(7), 1164-8, https://doi.org/10.1097/00005768-199807000-00023

Foster, C. (2001). Florhaug, J.A., Franklin, J., Gottschall, L., Hrovatin, L.A., Parker, S., Doleshal, P. \& Dodge, C. A new approach to monitoring exercise training. Journal of Strength and Conditioning Research, 15, 109-115, https://doi.org/10.1519/00124278-200102000-00019

Gomes, R.V., Coutts, A.J., Viveiros, L. \& Aoki, M.S. (2011). Physiological Demands of Match-Play in Elite Tennis : A Case Study. European Journal of Sport Science, 11(2), 105-109.

Gomes, R.V., Moreira, A., Lodo, L., Capitani, C.D. \& Aoki, M.S. (2015). Ecological Validity of Session RPE Method for Quantifying Internal Training Load in Tennis. International Journal of Sports Science \& Coaching, 10(4), 729-737, https://doi.org/10.1080/17461391.2010.487118

Haddad, M., Stylianides, G., Djaoui, L., Dellal, A. \& Chamari, K. (2017). Session-RPE method for training load monitoring: validity, ecological usefulness, and influencing factors. Frontiers in Neuroscience, 11, 612 , https://doi.org/10.3389/fnins.2017.00612

Kilpatrick, M.W., Martinez, N., Little, J.P., Jung, M.E., Jones, A.M., Price, N.W. \& Lende, D.H. (2015). Impact of HighIntensity Interval Duration on Perceived Exertion. Medicine \& Science in Sports \& Exercise, 47, 1038-1045, https://doi.org/10.1249/MSS.0000000000000495

Lockie, R.G., Murphy, A.J., Scott, B.R. \& Janse de Jonge, X.A.K. (2012). Quantifying session ratings of perceived exertion for field-based speed training methods in team sport athletes. Journal of Strength and Conditioning Research, 26(10),

2721-2728, https://doi.org/10.1519/JSC.0b013e3182429b0b

Murphy, A.P., Duffield, R., Kellett, A., and Reid, M. (2014). A Descriptive Analysis of Internal and External Loads for Elite-Level Tennis Drills. International Journal of Sports Physiology and Performance, 9, 863-870, https://doi.org/10.1123/ijspp.2013-0452

Murphy, A.P., Duffield, R., Kellett, A., Gescheit, D. \&Reid, M. (2015). The Effect of Predeparture Training Loads on Post-tour Physical Capacities in High-Performance Junior Tennis Players. International Journal of Sports Physiology and Performance, 10(8), 986-93, https://doi.org/10.1123/ijspp.2014-0374

Murphy, A.P., Duffield, R., Kellett, A. \& Reid, M. (2016). A comparison of the perceptual and technical demands of tennis training, simulated match play, and competitive tournaments. International Journal of Sports Physiology and Performance, 11(1), 40-47, https://doi.org/10.1123/ijspp.2014-0464

Perri, T., Norton, K.I., Bellenger, C.R. \& Murphy, A.P. (2018).
Training loads in typical junior-elite tennis training and competition: implications for transition periods in a highperformance pathway. International Journal of Performance Analysis in Sport, 18(2), 327-338, https://doi.org/10.1080/24748668.2018.1475198

Singh. F., Foster, C., Tod, D. \& McGuigan, M.R. (2007). Monitoring different types of resistance training using session rating of perceived exertion. International Journal of Sports Physiology and Performance, 2(1), 34-45, https://doi.org/10.1123/ijspp.2.1.34

RECOMMENDED ITF TENNIS ACADEMY CONTENT (CLICK BELOW)

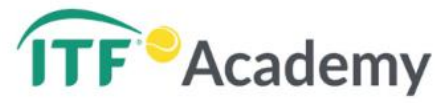

Copyright (c) 2020 Cyril Genevois, Isabelle Rogowski, \& Tom Le Solliec

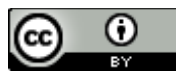

This text is under a Creative Commons BY 4.0 license

You are free to Share - copy and redistribute the material in any medium or format - and Adapt the content - remix, transform, and build upon the material for any purpose, even commercially under the following terms:

Attribution: You must give appropriate credit, provide a link to the license, and indicate if changes were made. You may do so in any reasonable manner, but not in any way that suggests the licensor endorses you or your use.

CCBY 4.0 license terms summary $\quad$ CCBY 4.0 license terms 